\title{
Review Article \\ Construction Formula of Biological Age Using the Principal Component Analysis
}

\author{
Linpei Jia, ${ }^{1}$ Weiguang Zhang, ${ }^{2}$ Rufu Jia, ${ }^{3}$ Hongliang Zhang, ${ }^{4}$ and Xiangmei Chen ${ }^{1,2}$ \\ ${ }^{1}$ Department of Nephrology, The Second Hospital of Jilin University, Ziqiang Street, No. 218, Changchun, Jilin 130041, China \\ ${ }^{2}$ Department of Nephrology, Chinese People's Liberation Army General Hospital, Chinese People's Liberation Army Institute of \\ Nephrology, State Key Laboratory of Kidney Disease, National Clinic Research Center for Kidney Diseases, Fuxing Road, \\ No. 28, Beijing 100853, China \\ ${ }^{3}$ Central Hospital of Cangzhou, Xinhua Middle Street, No. 201, Cangzhou, Hebei 061001, China \\ ${ }^{4}$ Department of Life Sciences, The National Natural Science Foundation of China, Shuangqing Road, No. 83, Beijing 100085, China \\ Correspondence should be addressed to Hongliang Zhang; drzhl@hotmail.com and Xiangmei Chen; xmchen301@126.com
}

Received 31 August 2016; Accepted 17 November 2016

Academic Editor: Barbara K. Pierscionek

Copyright (c) 2016 Linpei Jia et al. This is an open access article distributed under the Creative Commons Attribution License, which permits unrestricted use, distribution, and reproduction in any medium, provided the original work is properly cited.

\begin{abstract}
The biological age (BA) equation is a prediction model that utilizes an algorithm to combine various biological markers of ageing. Different from traditional concepts, the BA equation does not emphasize the importance of a golden index but focuses on using indices of vital organs to represent the senescence of whole body. This model has been used to assess the ageing process in a more precise way and may predict possible diseases better as compared with the chronological age (CA). The principal component analysis (PCA) is applied as one of the common and frequently used methods in the construction of the BA formula. Compared with other methods, PCA has its own study procedures and features. Herein we summarize the up-to-date knowledge about the BA formula construction and discuss the influential factors, so as to give an overview of BA estimate by PCA, including composition of samples, choices of test items, and selection of ageing biomarkers. We also discussed the advantages and disadvantages of PCA with reference to the construction mechanism, accuracy, and practicability of several common methods in the construction of the BA formula.
\end{abstract}

\section{Introduction}

Societies are currently facing a dramatic demographic change with an ever-increasing life expectancy, as well as an aged trend of population [1]. By 2050, the world population aged 80 and above will be more than triple, approaching 400 million individuals [2]. It is therefore urgent to plan a health administration to deal with or even prevent the senescence. Thus various studies aim at shedding light upon the mechanism of ageing and improving the life quality of the elderly [3-5]. These investigations have improved the search for ageing biomarkers to find ideal indices for evaluating or even predicting the ageing process. However, until now there has been no golden index for clinical or basic researches. Coasta and McCrae have pointed out that physical, physiological, or biochemical parameters alone or multivariate composition can only offer limited information regarding functional age in comparison to the chronological age (CA) [6].

To better evaluate the ageing process and predict the occurrence of ageing related diseases, the conception of biological age (BA) was proposed to describe the changes of body function with the same or similar CA in an objective way. The biological ageing is defined as a process or a group of processes that result in the progressive decrement of viability of the organism with advancing age [7]. Aiming at evaluating BA precisely, a kind of model was derived to construct a BA formula combining a series of ageing biomarkers with statistical method. This kind of BA formula aims at assessing the functional status during ageing as well as predicting ageing related diseases. Statistical methods that have been used for BA formula construction include the multiple linear 
regression (MLR), the principal component analysis (PCA), Hochschild's method, and the Klemera and Doubal method (KDM) [7-15]. Although some new methods other than PCA have been proposed and tested $[8,16]$, researchers still use PCA as a stable and common statistical method in some studies [12]. For example, PCA is better than MLR in avoiding some statistical deficiencies $[7,17,18]$.

Here, we searched studies on the construction of the BA formula via the PCA method, including both cross-sectional and longitudinal studies. Then we further summarized the basic process and the influential factors of constructing BA equation with PCA.

\section{Criteria of Subject Enrollment}

In previous studies, subject enrollment usually followed a series of standards (Table 1). First, all the subjects are healthy or almost healthy to exclude the impacts of diseases. Thus, the constructed formula can represent the normal ageing process or even works as a disease prediction model. Some researchers excluded all the unhealthy individuals and selected the healthy ones only [17-20, 23-25]. Volunteers who had been diagnosed with hypertension, diabetes, trauma, renal failure, mental disorder, stroke, cancer, heart failure, coronary heart disease, peripheral artery disease, pulmonary diseases, or a disease history within the last 6 months were excluded [17-20, 23-25]. However, since the senescence does not have an established cut-point with some diseases and subclinical conditions, the selections of subjects in some studies were not strictly performed. Some volunteers with hypertension, dyslipidemia, diabetes, and early impairment of organs were also included [7, 11, 21, 22]. Second, researchers need to control the size and constitution of samples. In early exploratory studies, the BA formulae of males and females were analyzed separately, and the sample size was usually small, which was often less than 100 people in most circumstances $[7,17,18,20,21]$. Then with the development of BA formula construction, the sample size was expanded accordingly [11, 12, 19, 23-25]. Meanwhile, both males and females were comparably included, and the ratio of two genders was near to $1: 1$ in many studies, which may avoid the sexual factors caused by the gender differences of ageing process [11, 12, 22-25]. The expanding sample size and balanced ratio of two genders are required to give deeper view of BA in the whole population. Third, volunteers aged over 18 years participated so as to cover all the age groups of adults, including youth, the middleaged, and the elderly. Ages distribute as evenly as possible to eliminate such bias. However, some researchers claimed that the age range should be from 30 to 80 by arguing that major organ functions begin to decline after 30 years and the people over 80 have their specific biological states that are different from younger people [23]. Though the age range of 30 to 80 years is a rigorous consideration, the exclusion of people aged younger than 30 or over 80 needs to be further discussed. Then the data of selected subjects were collected and analyzed to construct the BA equation.

\section{Candidate Test Items and Ageing Biomarkers}

3.1. Candidate Test Items. Ageing biomarkers were selected from tens or hundreds of test items (Table 2). The proper test items can reflect the ageing process of vital organs. The selection of test items is the foundation of BA formula construction. Some of the test items are routine clinical examinations, which help researchers to have a general understanding of the study subjects, such as age, gender, height, body fat, blood pressure, blood routine, blood chemistry, urine routine, and pulmonary function $[7,11,12,17-$ 25]. The routine examinations were included in nearly all of the studies about BA model construction. Beyond that, some other test items were used to explore better ageing biomarkers. Some researchers added cardiovascular examinations, including cardiac ultrasound, carotid artery ultrasound, and electrocardiograph $[7,12,23-25]$. Studies have validated that some parameters of cardiovascular examinations are good biomarkers in estimation of BA [12]. Since the elderly people have a higher risk of cardiovascular system disease, and the ageing process of cardiovascular system is typical [24]. The imaging examinations were also preferred by a small number of researchers, such as abdomen ultrasound, chest radiography, and gastrointestinal endoscopy [7, 12, 23]. Due to the relatively high cost, fuzzy evaluation standards, and radioaction, the use of imaging examinations in BA estimation is largely restricted. Ageing is not a single process and may be affected by various factors such as the environment, living habits, and heredity. In order to explore how the living habits affect the ageing, questionnaires were added to record the living habits of subjects [7, 12, 21, 24, 25]. In previous studies, many factors, including smoking status and exercise levels, were shown to have a close relationship with individual ageing [21]. The advanced technology of genetics prompted people to investigate whether genetic parameters can be selected as ageing biomarkers. Telomere restriction fragment (TRF) length is recognized as a genetic marker of ageing at the cellular level, which is associated with dynamic ageing [29-31]. Zhang et al. found that the TRF length has a positive correlation with CA and is closely related to ageing biomarkers [25]. When it comes to hormones, Bai's team selected estrogen (ESTR) as one of the test items, and they reported that ESTR was a significant predictor of BA in women only [12]. It is worth thinking that more sex hormones should be tested for providing a new way to estimate BA in different genders.

3.2. Ageing Biomarkers. Biomarkers of ageing are the composition of BA formula. It is important in the process of construction to select the proper biomarkers, because the more accurate the biomarkers are selected, the more precise the BA formula is. Generally, biomarkers of ageing come from the vital organs that are sensitive to body ageing. Common biomarkers are summarized in Table 3. Among all the biomarkers, systolic blood pressure (SBP) has a relatively higher frequency, followed by blood urea nitrogen (BUN) and forced expiratory volume in $1 \mathrm{~s}$ (FEV1). SBP is known as a major marker of cardiovascular system closely associated 
TABLE 1: The basic information of study population.

\begin{tabular}{|c|c|c|c|c|c|}
\hline Researcher & Year & Country & Sample size & Age range & Health standard \\
\hline $\begin{array}{l}\text { Nakamura et al. } \\
\text { [17] }\end{array}$ & 1989 & Japan & 69 males & $\begin{array}{c}\text { Average } 42.6 \pm 9.4 \\
\text { years }\end{array}$ & Healthy population \\
\hline $\begin{array}{l}\text { Nakamura et al. } \\
{[18]}\end{array}$ & 1990 & Japan & 66 females & 20-64 years & Healthy population \\
\hline $\begin{array}{l}\text { Nakamura et al. } \\
{[19]}\end{array}$ & 1996 & Japan & 221 males & $20-85$ years & Healthy population \\
\hline Ueno et al. [20] & 2003 & Japan & $\begin{array}{c}981 \text { females (cross-sectional } \\
\text { study) } \\
110 \text { females (longitudinal } \\
\text { study) }\end{array}$ & $20-80$ years & Healthy population \\
\hline $\begin{array}{l}\text { Nakamura and } \\
\text { Miyao [7] }\end{array}$ & 2003 & Japan & 86 males & $31-77$ years & $\begin{array}{l}\text { Healthy population, } \\
\text { including some volunteers } \\
\text { with hypertension, } \\
\text { hyperlipidemia, and } \\
\text { diabetes }\end{array}$ \\
\hline $\begin{array}{l}\text { Nakamura and } \\
\text { Miyao [21] }\end{array}$ & 2007 & Japan & 86 males & $31-78$ years & $\begin{array}{l}\text { Healthy population, } \\
\text { including some volunteers } \\
\text { with hypertension, } \\
\text { hyperlipidemia, and } \\
\text { diabetes }\end{array}$ \\
\hline $\begin{array}{l}\text { Nakamura and } \\
\text { Miyao [22] }\end{array}$ & 2008 & Japan & $\begin{array}{c}86 \text { males } \\
93 \text { females } \\
\text { Males }: \text { females }=0.925: 1\end{array}$ & $31-77$ years & $\begin{array}{l}\text { Healthy population, } \\
\text { including some volunteers } \\
\text { with hypertension, } \\
\text { hyperlipidemia, and } \\
\text { diabetes }\end{array}$ \\
\hline Park et al. [23] & 2009 & Korea & 1588 & $30-77$ years & Healthy population \\
\hline Bai et al. [12] & 2010 & China & $\begin{array}{c}392 \text { males } \\
460 \text { females } \\
\text { Males }: \text { females }=0.852: 1\end{array}$ & $30-98$ years & $\begin{array}{l}\text { Healthy population and } \\
\text { some volunteers with } \\
\text { subclinical state }\end{array}$ \\
\hline Jee et al. [11] & 2012 & Korea & $\begin{array}{c}1604 \text { males } \\
760 \text { females } \\
\text { Males }: \text { females }=2.111: 1\end{array}$ & $30-85$ years & $\begin{array}{l}\text { Healthy population and } \\
\text { some volunteers with early } \\
\text { state of diseases }\end{array}$ \\
\hline Zhang et al. [24] & 2014 & China & $\begin{array}{c}669 \text { males } \\
684 \text { females } \\
\text { Males : females }=0.978: 1\end{array}$ & $35-91$ years & Healthy population \\
\hline Zhang et al. [25] & 2014 & China & $\begin{array}{c}69 \text { males } \\
70 \text { females } \\
\text { Males }: \text { females }=0.986: 1\end{array}$ & $35-91$ years & Healthy population \\
\hline
\end{tabular}

with cardiovascular diseases. It appears that SBP increases steadily with ageing [32]. FEV1 represents the function of respiratory system. Some studies have reported that FEV1 is related to senescence and mortality [33]. Interestingly, two groups of researchers found that FEV1 was also associated with a substantial excess risk of cardiovascular diseases [34, 35]. Thus FEV1 could be a good biomarker of ageing. BUN is a traditional marker of renal function, while Cystatin $\mathrm{C}$ is a relatively new and more sensitive marker [36]. Cystatin $\mathrm{C}$ has a higher correlation with CA as compared with BUN $[12,24,25]$. Thus Cystatin $C$ may replace BUN as the new biomarker in BA formula construction.

Early studies focused on the indices of blood chemistry and blood routine, while the latter studies added some new test items, such as cardiovascular ultrasonography, nervous system tests, IL-6, and TRF length. Among them, indices of cardiovascular ultrasonography, TRF length, and nervous system are more sensitive with body ageing [12, 24, 25]. These test items push forward the research progress. It is worth mentioning that TRF length, a genetic parameter, breaks a new path in construction of BA model. Zhang et al. have found TRF length as a benchmark to select biomarkers of ageing to build BA equation instead of CA, since TRF length has a positive correlation with CA and is closely related to other ageing biomarkers [25]. Application of TRF length indicates that other genetic markers, such as single nucleotide polymorphism (SNP), methylation, and copy number variation (CNV), may also be new benchmarks to select biomarkers of ageing $[25,31]$.

In many studies, parameters of respiratory system have the relatively higher coefficient with CA, especially FEV1 and forced vital capacity (FVC) $[7,11,17,20,22,23]$. The $r$ values of these two indices are always greater than 0.50 , which shows a close relation between BA and respiratory system. Because 
TABLE 2: General description of test items.

\begin{tabular}{lc}
\hline Test items & Researches \\
\hline Basic information (age, gender, height, & {$[7,11,12,17-25]$} \\
body fat, and blood pressure) & {$[7,12,17-25]$} \\
Blood routine & {$[7,12,17-25]$} \\
Blood chemistry & {$[7,12,20-25]$} \\
Urine routine & {$[7,12,17-24]$} \\
Pulmonary function & {$[12,24,25]$} \\
Cardiovascular ultrasound & {$[12,24,25]$} \\
Carotid artery ultrasound & {$[12]$} \\
Sexual hormone & {$[7,12,23,25]$} \\
Electrocardiograph & {$[7,12,23]$} \\
Chest radiography & {$[23]$} \\
Abdomen ultrasound & {$[23]$} \\
Gastrointestinal endoscopy & {$[7,12,21,24,25]$} \\
Questionnaire of living habits & {$[24,25]$} \\
Genetics &
\end{tabular}

other indices of respiratory system are not often included, a further study needs to be done. Moreover, SBP, pulse pressure (PP), mitral valve annulus lateral wall of peak velocity of early filling (MVEL), and mitral valve annulus inferior wall of peak velocity of early filling (MVEI) are found to have higher coefficients with CA, respectively $[12,18,24,25]$. Both MVEL and MVEI are relatively new biomarkers of ageing, and the accuracy needs to be verified in the future.

\section{Basic Steps of Construction BA Formula Using PCA}

The method of building BA equation using PCA usually consists of five steps: correlation analysis, stability analysis, redundancy analysis, PCA, and the equation construction (Figure 1).

Because candidate biomarkers of ageing are expected to show evidence of changes with passage of time, correlation analysis is the first step to exclude the indices that have low coefficients of correlation with CA. By correlation analysis, some of the indices, which have high relation with CA and reflect the ageing process of body, are selected as candidates of ageing biomarkers for further analyzing.

The second step is stability analysis, which only exists in longitudinal analysis. Stability analysis is used to examine the degree of longitudinal stability of individual differences to evaluate the interyear reliability of annual values of each index [20]. Considering the results of correlation analysis, indices with a higher correlation with CA and keeping stable in succeeding years are selected.

Some of the indices selected by correlation analyses and stability analyses come from one vital organ and evaluate the same part of body function; for example, both pressure pulse and SBP reflect the conditions of the vascular system. Thus redundancy analysis is the third step to eliminate the repeated indices. In redundancy analysis, correlations of each of the

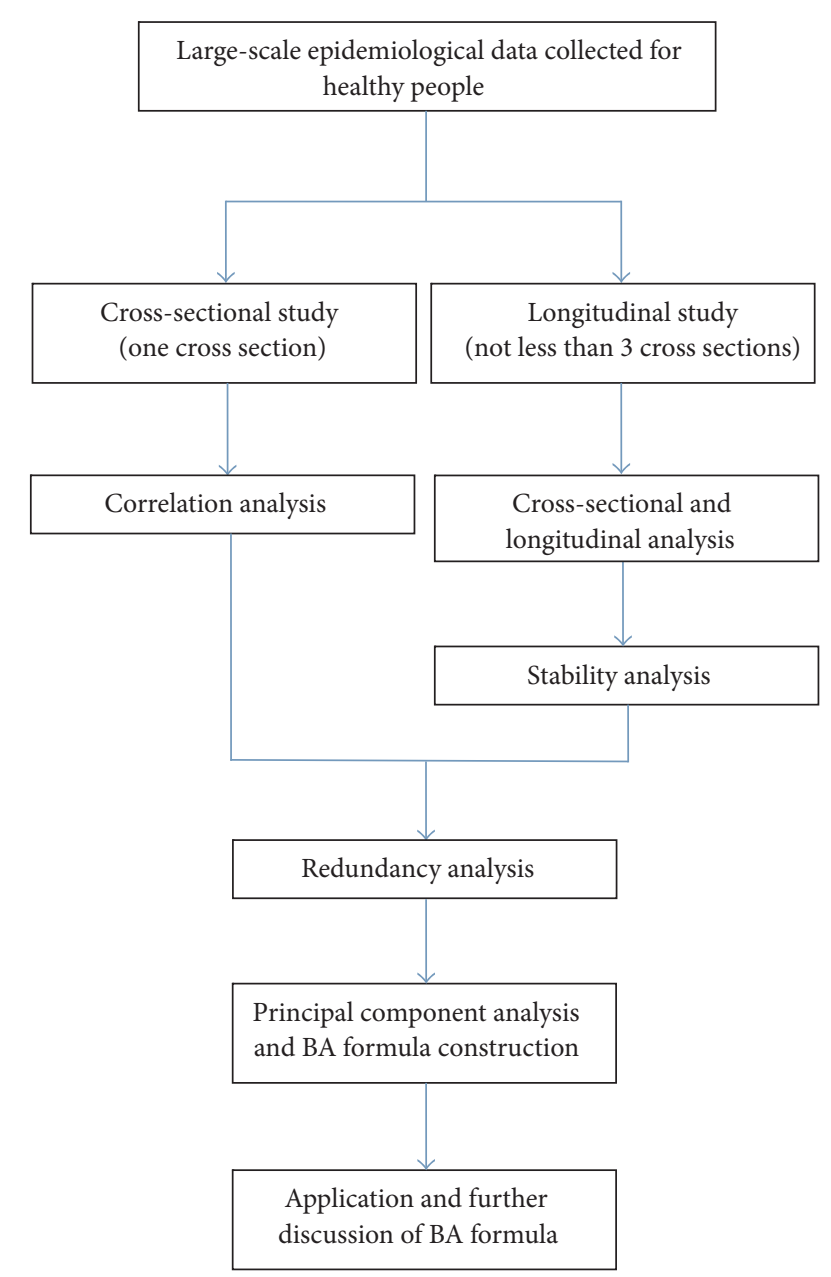

FIGURE 1: Flow chart of basic steps of biological age model constructions by principal component analysis.

two indices are calculated, and the pair of indices with high coefficient is defined as repeated indices. The one with higher correlation with CA is selected.

Then PCA is applied to reduce the dimension of the variables. Indices with eigenvalues greater than 1.0 are determined as principal components, and the greater one is called the first principal component. Other variables load onto the first principal component to explain the variation of BA. Two kinds of PCA are done, with CA and without CA. PCA with CA determines the relationship between CA and principal components. While PCA without CA is used to show whether the relationships will be held without the influence of CA. Hence the biomarkers of ageing are selected.

In the last step of formula construction, the formula of biological age score $(\mathrm{BAS})=a *\left(X_{1}-\right.$ mean $\left._{1}\right) / \mathrm{SD}_{1}+b *$ $\left(X_{2}-\operatorname{mean}_{2}\right) / \mathrm{SD}_{2}+c * X_{3}+\cdots n *\left(X_{n}-\right.$ mean $\left._{n}\right) / \mathrm{SD}_{n}$. Here $n$ is the coefficient score, $X_{n}$ is the biomarker, mean $n_{n}$ is the mean value of $X_{n}$, and $\mathrm{SD}_{n}$ is the standard deviation of $X_{n}$. Some researches would like to transform BAS to BA, because the unit of BAS is not year. The following method is applied to transform BAS to BA: $\mathrm{BA}=\mathrm{BAS}$ (the standard deviation of $\mathrm{CA}$ ) + the mean of CA. Because the BA formula 
TABLE 3: Biomarkers of ageing.

\begin{tabular}{|c|c|c|}
\hline Organ system & Biomarker & Epidemiologic studies \\
\hline \multirow{10}{*}{ Cardiovascular system } & Pulse pressure & {$[12,25]$} \\
\hline & Systolic blood pressure & {$[11,17-23]$} \\
\hline & Heart rate & {$[17,18]$} \\
\hline & Intima-media thickness & {$[12,24,25]$} \\
\hline & Maximum internal diameter of carotid artery & {$[24,25]$} \\
\hline & End diastolic velocity & {$[12]$} \\
\hline & Mitral valve annulus ventricular septum of the peak velocity of early filling & {$[24]$} \\
\hline & Mitral valve annulus lateral wall of peak velocity of early filling & {$[12]$} \\
\hline & Mitral annulus peak E anterior wall & {$[25]$} \\
\hline & Ratio of peak velocity of early filling to atrial filling & {$[12]$} \\
\hline \multirow{4}{*}{ Respiratory system } & $V_{\mathrm{O}_{2} \max }$ & {$[11,23]$} \\
\hline & Forced expiratory volume in $1 \mathrm{~s}$ & {$[11,20-23]$} \\
\hline & Forced vital capacity & [17-19] \\
\hline & Maximal midexpiratory flow rate $75 / 25$ & {$[24]$} \\
\hline \multirow{2}{*}{ Nervous system } & Trail making test & [24] \\
\hline & Digital symbol test & {$[25]$} \\
\hline \multirow{2}{*}{ Renal system } & Blood urea nitrogen & {$[17-19,21-23]$} \\
\hline & Cystatin C & {$[12,24,25]$} \\
\hline \multirow{5}{*}{ Liver } & Serum albumin & {$[21-23]$} \\
\hline & Glutamic oxaloacetic transaminase & {$[17,18]$} \\
\hline & Glutamic pyruvic transaminase & {$[19]$} \\
\hline & Ratio of albumin to globulin & [20] \\
\hline & Lactate dehydrogenase & {$[17-19]$} \\
\hline \multirow{6}{*}{ Hematologic system } & Erythrocyte sedimentation rate & [23] \\
\hline & Mean corpuscular hemoglobin & {$[20]$} \\
\hline & Red blood cell count & {$[22]$} \\
\hline & Hematocrit & {$[21]$} \\
\hline & Haemoglobin concentration & {$[18,19]$} \\
\hline & Fibrinogen & {$[12]$} \\
\hline \multirow{6}{*}{ Metabolism } & Glycosylated hemoglobin & {$[23]$} \\
\hline & Glucose & {$[19,20]$} \\
\hline & Low density cholesterol & {$[23]$} \\
\hline & Atherogenic index & {$[17,18]$} \\
\hline & Triglyceride & {$[18]$} \\
\hline & Total cholesterol concentration & [19] \\
\hline \multirow{4}{*}{ Muscle and fat } & Grip strength & {$[11]$} \\
\hline & Soft lean mass & {$[11]$} \\
\hline & Waist circumference & {$[11,23]$} \\
\hline & Percent body fat & {$[23]$} \\
\hline Sensory system & Hearing threshold & {$[23]$} \\
\hline Genetic index & Telomere restriction fragment & [25] \\
\hline
\end{tabular}

is underestimated of the means of BA for the upper end of regression and overestimated for the lower end, researchers correct the formula using the following: corrected $\mathrm{BA}=\mathrm{BA}$ $+Z$. $Z$ means $\left(y_{i}-y\right)(1-b) \cdot y_{i}$ is the individual's CA and $y$ is the average of CA. $b$ stands for the coefficient of linear regression between $\mathrm{CA}$ and $\mathrm{BA}$ [7]. Here the formula of $\mathrm{BA}$ is constructed.

\section{Statistical Points in BA Formula Construction Using PCA}

5.1. Correlation Coefficient and Redundancy Coefficient. Correlation coefficient and redundancy coefficient are two main parameters in correlation analysis and redundancy analysis. They are the criteria of selection of ageing biomarkers and 
TABLE 4: Correlation coefficients and redundancy coefficients of each research.

\begin{tabular}{lccc}
\hline Researcher & Year & $\begin{array}{c}\text { Correlation } \\
\text { coefficient }\end{array}$ & $\begin{array}{c}\text { Redundancy } \\
\text { coefficient }\end{array}$ \\
\hline Nakamura et al. [17] & 1989 & 0.24 & 0.5 \\
Ueno et al. [20] & 2003 & 0.25 & 0.9 \\
Nakamura and Miyao & 2007 & & 0.6 \\
[21] & & & \\
Nakamura and Miyao & 2008 & & 0.6 \\
[22] & 2009 & 0.15 & \\
Park et al. [23] & 2010 & 0.25 & 0.4 \\
Bai et al. [12] & 2012 & 0.12 & 0.75 \\
Jee et al. [11] & 2014 & 0.40 & 0.7 \\
Zhang et al. [24] & 2014 & 0.15 & 0.7 \\
Zhang et al. [25] & & &
\end{tabular}

decided by the quality of indices. Wedam has interpreted $r$ as follows: $r>0.7$ means a strong correlation; $0.5<r<0.7$ means moderate correlation; $0.3<r<0.5$ means weak to moderate correlation; $r<0.3$ means weak correlation [37]. The $P$ value only indicated whether the test of $r=0$ is right; herein the stress should be put on the value of $r$ [37].

The coefficients of different studies are not unified and range from 0.12 to 0.40 (Table 4). Disparities of coefficients may arise from the selection of test items and the research requirements. Because some of the examinations better reflect the senescence of vital organs, the coefficient would be higher if these examinations are included. In the early studies, the correlation coefficients were relatively low, because the test items were mainly focused on the common examinations in clinical practice, such as blood routine, blood chemistry, and urine routine [17, 20,23]. With the exploration of new ageing biomarkers, new test items are added into the researches, such as cardiovascular ultrasound, carotid artery ultrasound, and some inflammatory cytokines [12, 24]. New test items improve the relevance with chronological age as well as the correlation coefficient.

Coefficient of redundancy analysis is usually more than 0.6 (Table 4). However, the coefficient is not fixed, since the selection of indices is not based on the statistical analysis only, but also considered of clinical factors and requirement of the research. Certainly, a higher coefficient means better quality of data.

5.2. PCA versus Other Methods. Common methods of BA estimates include MLR, PCA, Hochschild's method, and KDM. MLR of CA has long been used for the calculation of BA, whereas multiple regression of equation overestimates individual BA for young people and underestimates those for the elderly [23]. Some researchers found that the distortion of the BA at the regression edge is influenced by mathematical factors of MLR, and this method also ignores the discontinuity of the ageing rate during the whole life of individuals $[9,27,28]$. Because in PCA method we use the fewer uncorrelated variables to explain the most variance, instead of combining different variables into a regression equation, PCA avoids some of the statistical deficiencies of MLR [28]. Though PCA has some advantages compared to MLR to some extent, it may not be the best formula of BA estimation. Some new methods such as the KDM and Hochschild's method have been tested and appeared better than PCA [26]. Specifically, Levine compared BA estimation constructed by MLR, PCA, and the KDM in a longitudinal study and found that the KDM was the most reliable predictor of mortality which performed significantly better than the other two methods [16]. However, the outstanding KDM seems to be complicated in computation [26]. Comparisons among MLR, PCA, Hochschild's method, and KDM are shown in Table 5.

\section{Discipline of Ageing}

6.1. Why Do Women Have a Longer Lifespan Than Men? Usually women have a longer life span than men. To explore the potential causes of such a phenomenon, the BA formula constructed by PCA is widely used in discussions of sexual differences. By using BA formula, some researchers found that although women have a lower biological vigor than men in early adulthood, the ageing rate of women is up to 1.4-fold slower than that of men $[11,21,22]$, which may explain the average longevity of women.

6.2. The Ageing Rate Is Not Constant during the Whole Life of Human Beings. According to the previous studies, the ageing rate is not constant through the whole life of human, and it seems to follow an exponential curve. For both men and women, the ageing rate increases slowly before the age of 65 years; then the rates of ageing rapidly advance [21, 22]. Compared with younger people, the rate of the elders is 1.8fold [21]. The higher ageing rate can explain why there are more diseases and higher death rate in the elders. However, Bai's study showed a little difference, which reported that there is no difference between the ageing rates of people from 65 to 75 years old and people above 75 years old. This had not been reported since other researchers did not give a more detailed division of people over 65 years old [12]. Bai et al. explained this phenomenon as the stability of ageing process over 75 years old.

\section{Concluding Remarks}

With the development of the BA formula, PCA was proposed in BA studies, which may avoid some of the statistical deficiencies of the MLR method [27]. Though the KDM appeared better than PCA method, the relatively simple calculation procedures still allow the PCA method to be preferable in many recent studies $[12,24,25]$. At the same time, since the BA formula is a prediction model, its utility is necessary to be tested. Future studies may be focused on the mortality prediction and the clinical application, which will pull the BA formula changing from theoretical model to practical method. Ideal ageing biomarkers can assure the veracity of the BA equation. At present, although we have developed a large amount of test items for selection of ageing 
TABLE 5: Comparisons between the multiple linear regression (MLR), the principal component analysis (PCA), Hochschild's method, and the Klemera and Doubal method (KDM) in biological age (BA) estimates.

\begin{tabular}{|c|c|c|}
\hline Methods & Advantages & Disadvantages \\
\hline MLR & $\begin{array}{l}\text { As an initial method of BA estimates, MLR can detect } \\
\text { the stabilization and multicollinearity of the empirical } \\
\text { data [26]. }\end{array}$ & $\begin{array}{l}\text { The distortion of BA at the regression edge is influenced } \\
\text { by mathematical factors, and MLR also ignores the } \\
\text { discontinuity of the ageing rate during the whole life of } \\
\text { individuals }[9,27,28] \text {. The BA formula established by } \\
\text { MLR is probably disserviceable [8]. }\end{array}$ \\
\hline PCA & $\begin{array}{l}\text { PCA selects and transforms the original biomarkers to } \\
\text { a reduced and/or transformed new series of } \\
\text { uncorrelated variables [8]. PCA avoids the influence of } \\
\text { regression edge in MLR [28] and is easy to be operated. } \\
\text { This method generates the uncorrelated variables and } \\
\text { provides the information of underlying structure of } \\
\text { variables [26]. }\end{array}$ & $\begin{array}{l}\text { The final step of the computation resembles the MLR } \\
\text { method, and some of the statistical deficiencies of MLR } \\
\text { cannot be totally avoided [8]. }\end{array}$ \\
\hline $\begin{array}{l}\text { Hochschild's } \\
\text { method }\end{array}$ & $\begin{array}{l}\text { Hochschild's method uses the regression for individual } \\
\text { biomarkers and evaluates the biomarkers according to } \\
\text { their impact on life expectancy [8]. }\end{array}$ & $\begin{array}{l}\text { Hochschild's method is not based on mathematical } \\
\text { definition of BA, and the construction mechanism is } \\
\text { elusive. In particular, the calculation does not } \\
\text { correspond to the optimum algorithm [8]. Moreover, a } \\
\text { large number of subjects are needed to be measured } \\
\text { when Hochschild's method is adopted for a newly } \\
\text { developed system [26]. }\end{array}$ \\
\hline $\mathrm{KDM}$ & $\begin{array}{l}\text { KDM is a more reliable predictor of mortality and } \\
\text { performed better than the chronological age [16]. KDM } \\
\text { gives lower errors than other methods, evaluates the } \\
\text { precision of BA estimates, and solves the paradox of } \\
\text { biomarker selection according to CA [8]. }\end{array}$ & KDM requires complicated calculations [26]. \\
\hline
\end{tabular}

biomarkers, many possible better biomarkers are still waiting to be found, and TRF length is a good start. The future studies may pay more attention to genetic biomarkers in ageing. We believe that studies of constructing BA formula with PCA will become more complete not only in the methodology, but also in the clinical application.

\section{Competing Interests}

None of the authors stated any conflict of interests.

\section{Authors' Contributions}

Hongliang Zhang and Xiangmei Chen contributed equally to the article as the correspondence authors.

\section{Acknowledgments}

The study was supported by grants from the Major State Basic Research Development Program of China (2013CB530800), the National Natural Science Foundation of China (81270819), and the National Key Technology R\&D Program (2011BAI10B00).

\section{References}

[1] S. M. Steculorum and J. C. Brüning, "Die another day: a painless path to longevity," Cell, vol. 157, no. 5, pp. 1004-1006, 2014.

[2] S. Harper, "Economic and social implications of aging societies," Science, vol. 346, no. 6209, pp. 587-591, 2014.
[3] C. Yee, W. Yang, and S. Hekimi, "The intrinsic apoptosis pathway mediates the pro-longevity response to mitochondrial ROS in C. elegans," Cell, vol. 157, no. 4, pp. 897-909, 2014.

[4] M. S. Denzel, N. J. Storm, A. Gutschmidt et al., "Hexosamine pathway metabolites enhance protein quality control and prolong life," Cell, vol. 156, no. 6, pp. 1167-1178, 2014.

[5] C. E. Riera, M. O. Huising, P. Follett et al., “TRPV1 pain receptors regulate longevity and metabolism by neuropeptide signaling," Cell, vol. 157, no. 5, pp. 1023-1036, 2014.

[6] P. T. Coasta and R. R. McCrae, "Concepts of functional or biological age," in Principals of Geriatric Medicine, pp. 30-37, McGraw Hill, New York, 1985.

[7] E. Nakamura and K. Miyao, "Further evaluation of the basic nature of the human biological aging process based on a factor analysis of age-related physiological variables," Journals of Gerontology, Series A: Biological Sciences and Medical Sciences, vol. 58, no. 3, pp. 196-204, 2003.

[8] P. Klemera and S. Doubal, "A new approach to the concept and computation of biological age," Mechanisms of Ageing and Development, vol. 127, no. 3, pp. 240-248, 2006.

[9] T. L. Dubina, V. A. Dyundikova, and E. V. Zhuk, "Biological age and its estimation. II. Assessment of biological age of albino rats by multiple regression analysis," Experimental Gerontology, vol. 18, no. 1, pp. 5-18, 1983.

[10] V. P. Voitenko and A. V. Tokar, “The assessment of biological age and sex differences of human aging," Experimental Aging Research, vol. 9, no. 4, pp. 239-244, 1983.

[11] H. Jee, B. H. Jeon, Y. H. Kim et al., "Development and application of biological age prediction models with physical fitness and physiological components in Korean adults," Gerontology, vol. 58, no. 4, pp. 344-353, 2012. 
[12] X. Bai, L. Han, Q. Liu et al., "Evaluation of biological aging process-a population-based study of healthy people in China," Gerontology, vol. 56, no. 2, pp. 129-140, 2010.

[13] R. Hochschild, "Improving the precision of biological age determinations. Part 1: a new approach to calculating biological age," Experimental Gerontology, vol. 24, no. 4, pp. 289-300, 1989.

[14] R. Hochschild, "Improving the precision of biological age determinations. Part 2: automatic human tests, age norms and variability," Experimental Gerontology, vol. 24, no. 4, pp. 301-316, 1989.

[15] D. H. Lang, D. E. Conroy, A. Lionikas et al., "Bone, muscle, and physical activity: Structural equation modeling of relationships and genetic influence with age," Journal of Bone and Mineral Research, vol. 24, no. 9, pp. 1608-1617, 2009.

[16] M. E. Levine, "Modeling the rate of senescence: can estimated biological age predict mortality more accurately than chronological age?" Journals of Gerontology Series A: Biological Sciences and Medical Sciences, vol. 68, no. 6, pp. 667-674, 2013.

[17] E. Nakamura, T. Moritani, and A. Kanetaka, "Biological age versus physical fitness age," European Journal of Applied Physiology and Occupational Physiology, vol. 58, no. 7, pp. 778-785, 1989.

[18] E. Nakamura, T. Moritani, and A. Kanetaka, "Biological age versus physical fitness age in women," European Journal of Applied Physiology and Occupational Physiology, vol. 61, no. 3-4, pp. 202-208, 1990.

[19] E. Nakamura, T. Moritani, and A. Kanetaka, "Effects of habitual physical exercise on physiological age in men aged $20-85$ years as estimated using principal component analysis," European Journal of Applied Physiology and Occupational Physiology, vol. 73, no. 5, pp. 410-418, 1996.

[20] L. M. Ueno, Y. Yamashita, T. Moritani, and E. Nakamura, "Biomarkers of aging in women and the rate of longitudinal changes," Journal of Physiological Anthropology and Applied Human Science, vol. 22, no. 1, pp. 37-46, 2003.

[21] E. Nakamura and K. Miyao, "A method for identifying biomarkers of aging and constructing an index of biological age in humans," The Journals of Gerontology, Series A: Biological Sciences and Medical Sciences, vol. 62, no. 10, pp. 1096-1105, 2007.

[22] E. Nakamura and K. Miyao, "Sex differences in human biological aging," The Journals of Gerontology Series A: Biological Sciences and Medical Sciences, vol. 63, no. 9, pp. 936-944, 2008.

[23] J. Park, B. Cho, H. Kwon, and C. Lee, "Developing a biological age assessment equation using principal component analysis and clinical biomarkers of aging in Korean men," Archives of Gerontology and Geriatrics, vol. 49, no. 1, pp. 7-12, 2009.

[24] W.-G. Zhang, X.-J. Bai, X.-F. Sun et al., "Construction of an integral formula of biological age for a healthy Chinese population using principle component analysis," The Journal of Nutrition, Health and Aging, vol. 18, no. 2, pp. 137-142, 2014.

[25] W.-G. Zhang, S.-Y. Zhu, X.-J. Bai et al., "Select aging biomarkers based on telomere length and chronological age to build a biological age equation,” Age, vol. 36, no. 3, article 9639, 2014.

[26] I. H. Cho, K. S. Park, and C. J. Lim, "An empirical comparative study on biological age estimation algorithms with an application of Work Ability Index (WAI)," Mechanisms of Ageing and Development, vol. 131, no. 2, pp. 69-78, 2010.

[27] I. W. Webster and A. R. Logie, "A relationship between functional age and health status in female subjects," Journals of Gerontology, vol. 31, no. 5, pp. 546-550, 1976.
[28] E. Nakamura, K. Miyao, and T. Ozeki, "Assessment of biological age by principal component analysis," Mechanisms of Ageing and Development, vol. 46, no. 1-3, pp. 1-18, 1988.

[29] T. von Zglinicki and C. M. Martin-Ruiz, "Telomeres as biomarkers for ageing and age-related diseases," Current Molecular Medicine, vol. 5, no. 2, pp. 197-203, 2005.

[30] K. A. Mather, A. F. Jorm, R. A. Parslow, and H. Christensen, "Is telomere length a biomarker of aging? A review," Journals of Gerontology-Series A Biological Sciences and Medical Sciences, vol. 66, no. 2, pp. 202-213, 2011.

[31] W.-G. Zhang, Y. Wang, K. Hou et al., "A correlation study of telomere length in peripheral blood leukocytes and kidney function with age," Molecular Medicine Reports, vol. 11, no. 6, pp. 4359-4364, 2015.

[32] V. L. Burt, P. Whelton, E. J. Roccella et al., "Prevalence of hypertension in the US adult population. Results from the Third National Health and Nutrition Examination Survey, 1988-1991," Hypertension, vol. 25, no. 3, pp. 305-313, 1995.

[33] N. R. Cook, D. A. Evans, P. A. Scherr, F. E. Speizer, J. O. Taylor, and C. H. Hennekens, "Peak expiratory flow rate and 5 -year mortality in an elderly population," American Journal of Epidemiology, vol. 133, no. 8, pp. 784-794, 1991.

[34] W. B. Kannel and D. L. McGee, "Update on some epidemiologic features of intermittent claudication: the Framingham Study," Journal of the American Geriatrics Society, vol. 33, no. 1, pp. 13$18,1985$.

[35] S. T. Weiss, M. R. Segal, D. Sparrow, and C. Wager, "Relation of FEV1 and peripheral blood leukocyte count to total mortality. The normative aging study," American Journal of Epidemiology, vol. 142, no. 5, pp. 493-498, 1995.

[36] S. Lopez-Giacoman and M. Madero, "Biomarkers in chronic kidney disease, from kidney function to kidney damage," World Journal of Nephrology, vol. 4, no. 1, pp. 57-73, 2015.

[37] S. B. Wedam, J. A. Low, S. X. Yang et al., "Antiangiogenic and antitumor effects of bevacizumab in patients with inflammatory and locally advanced breast cancer," Journal of Clinical Oncology, vol. 24, no. 5, pp. 769-777, 2006. 


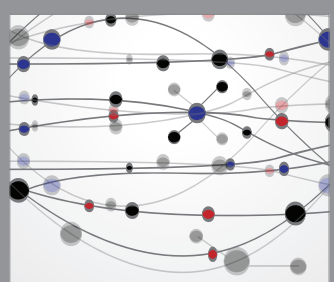

The Scientific World Journal
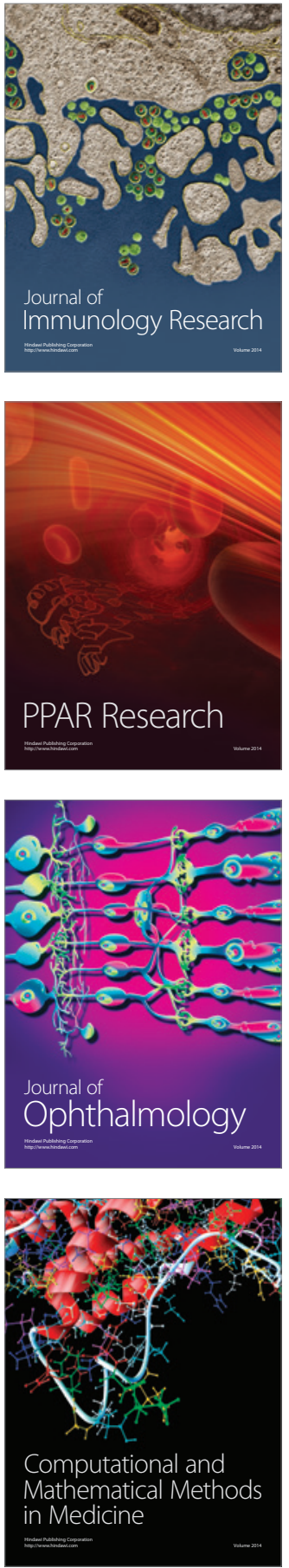

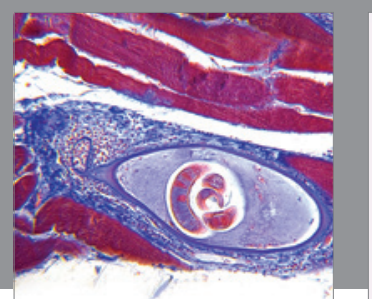

Gastroenterology Research and Practice

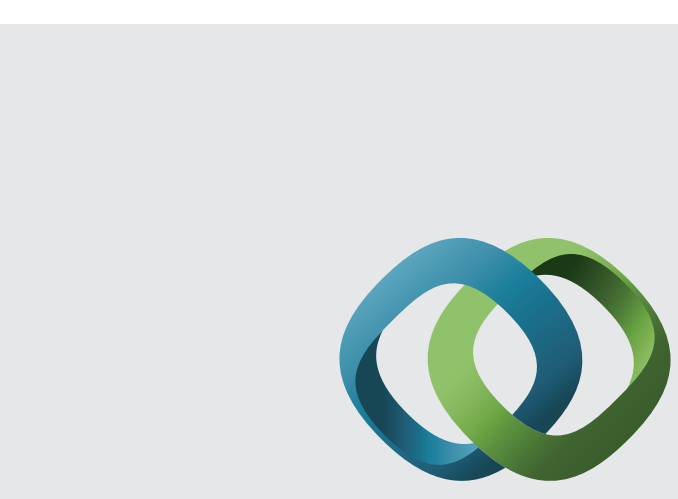

\section{Hindawi}

Submit your manuscripts at

http://www.hindawi.com
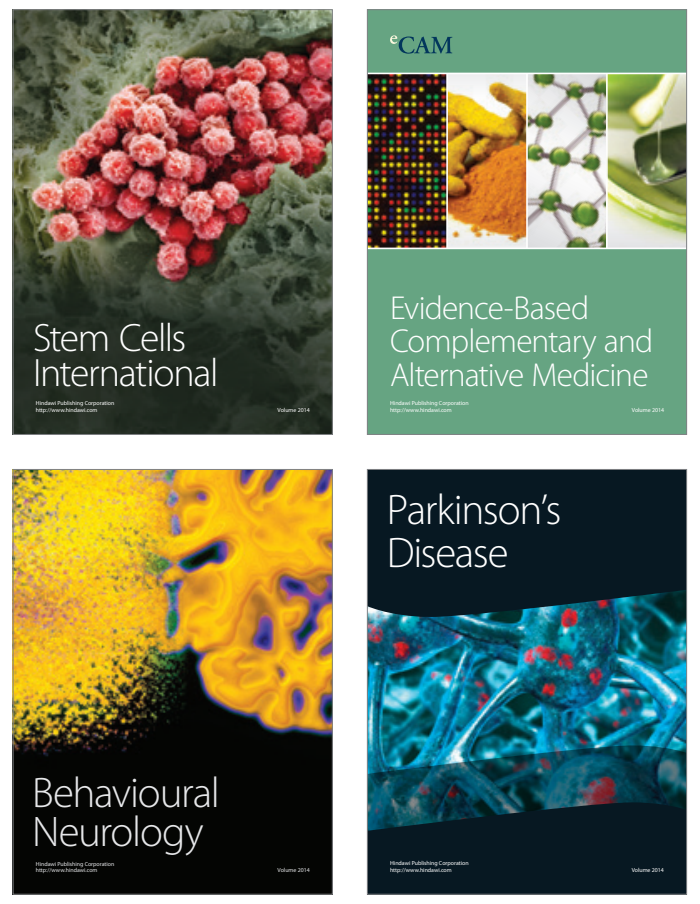
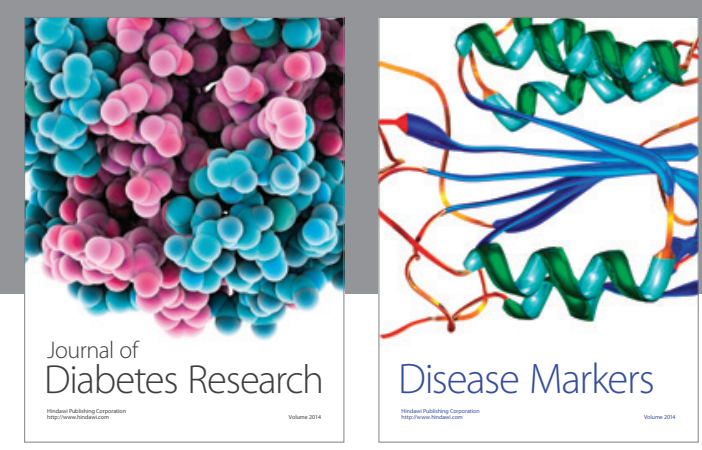

Disease Markers
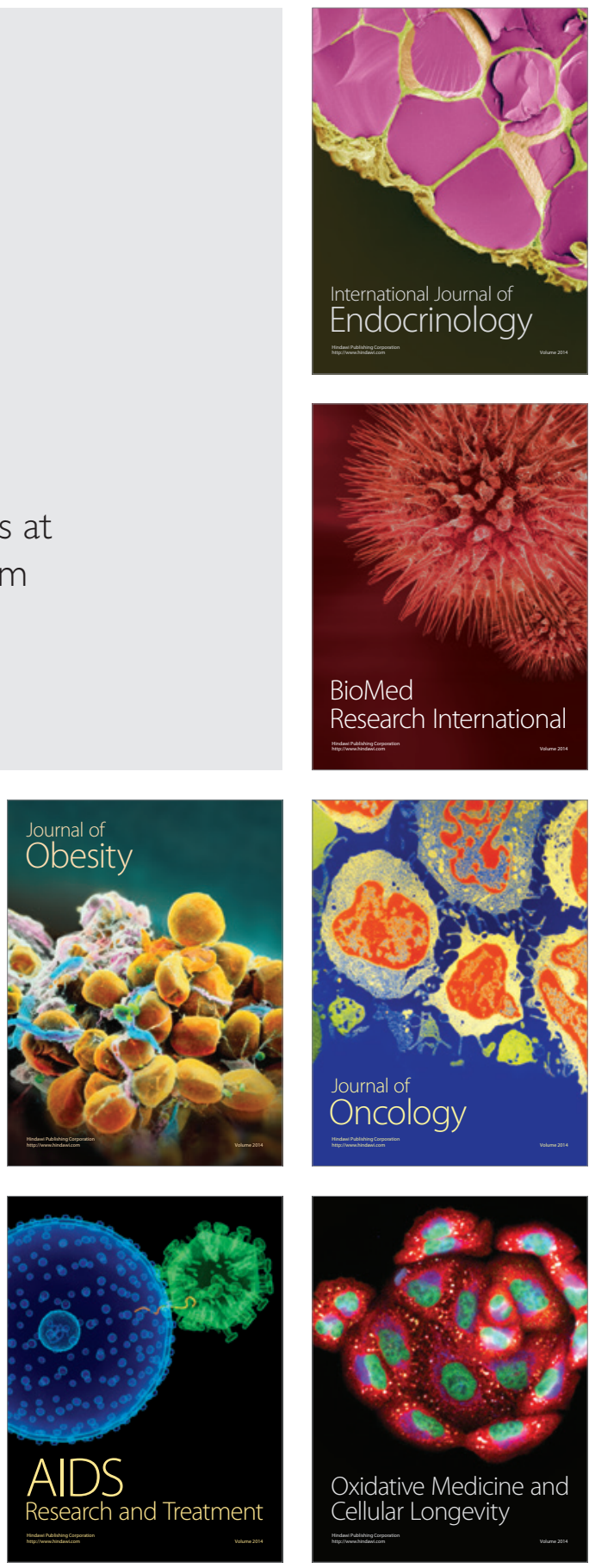